\title{
Economics and Risk *
}

\author{
by Ubaldo Nieto de Alba **
}

The concepts of risk and uncertainty are rather unclear in the textbooks and in ordinary language. Therefore, I believe that they should be approached from the statistical, actuarial and economic points of view. From the purely statistical angle, a risk exists whenever it can be measured statistically - that is, whenever probabilities can be identified and estimated. This is very important because, as we shall see, not all risks will prove to be insurable. It must be possible to measure them statistically. Here I am not raising the question of whether this statistical measurement is to be made objectively or by the Bayesian concept, but I am making it clear that the statistical concept of risk implies that the risk is statistically measurable.

Then there is the actuarial aspect. Do we take into account only that events occur - accidents, for example ? For the actuary, the economic consequences, such as compensation and capital, of these events are also important. In addition, the events occur at a given time, and so when we combine probability, capital and profitability we find that we are dealing with an actuarial situation which requires financial evaluation. It is also very important for the actuary to bear in mind that insurable risks are not an abstract concept but require an insurance company which will cover them. The reliability of this company is of the utmost importance. Thus the concept of risk also includes the reliability of the insurance company. In the premiums, the actuary has to allow for technical reserves, re-insurance and safety surcharges in order to keep the company's solvency within safe limits.

Now that we have defined the concept of risk from the statistical and actuarial viewpoints, we can turn to the economic aspect. Here, we must introduce the economic subject or agent, the decision taker. It has been said that "homo economicus" of traditional economics has become "homo stocasticus" - the man who has to take a decision in terms of probability. Classical economic theory is based entirely on the assumption of certainty. This is a determinist approach, which was abandoned by Physics a long time ago. The approach must rather be made on the basis of probability. The variables in economic balance must be regarded as "stochastic variables" with some probability elements. This is called " the economics of uncertainty." All problems of economic balance are defined in terms of probability.

In economics we cannot disregard the economic agent or subject, the decision taker. This brings in a concept of risk involving the decision taker. How does the

* Presented in Madrid to the General Assembly of the "Geneva Association" on 9th July 1979.

** Professor at the University of Alcala, Madrid. 
economic subject weigh one decision against another? Not all economic subjects regard risks in the same light. One insurer may consider a transactions in which he could lose a million pesetas a high risk whereas another would view it as normal. In the theory of decision-making this is called an order of preference. One cannot speak of decisions without taking into account each decision-taker's preference as regards risks. Each has his order of preference, and through the so-called "utility function", this brings us to the mathematical premises of the problem. So, "homo stocasticus", posing problems in terms of risk and uncertainty, has to become "homo politicus ", making decisions in a situation where he has to co-operate and compete with other economic agents. With the entry of the decision-taking agent, the concept of uncertainty arises. It is common to all decision making - for instance, construction, mining and the export sector all entail risk. But the economic subject who will take the decisions in these activities has available to him certain information. If he has very little information, he is said to be in a very uncertain situation. Imagine, for example, if $\mathrm{I}$, a university professor, were to engage in construction activities : such activities involve inherent economic risks about which I know very little since construction is not my job. Therefore economic agents who take decisions must be real professionals who are very well informed and thoroughly familiar with the risks peculiar to their sector so that the uncertainty is minimized.

This introduces some concepts very fashionable in present-day economics - risk and uncertainty, known also as information economics or informed economics. The mathematical techniques for measuring them which are already almost part of everyday jargon are also introduced. This is the Physics concept of the disorganization of the universe, which is measured as entropy. Entropy is what measures the uncertainty of a system. Naturally, this measurement is made in terms of the probability of events occurring and providing information. How can we neutralize this disorder and uncertainty? We can do it by means of information. The economic subject confronts that external disorder with the information which he acquires progressively through a process of apprenticeship, as he become familiar with the problems surrounding him. But what I want to highlight now (abandoning purely scientific aspects) is the origin of risk. The risks facing the economic agent originate in the environment in which he makes his decisions. The aforegoing helps us to see the relationship between the environment and the agent's willingness or reluctance to accept risks. We shall also see that all this is related to initiative, creativity and technological progress. It is not possible to raise the question of how an agent - specifically the insurer - accepts risks without taking into account the socio-economic environment in which he makes his decision.

Any brief description of the various types of economic environment must refer to the concept of economic organization which is characterized, first, by the system of ownership : the acceptance of risks differs greatly according to whether this ownership is collective, private, or in the hands of the State. Secondly, it is characterized by the economic order, i.e. how resources are allocated and decisions co-ordinated. In the world today, there are centralised economic systems where ownership is in the hands of the State, co-ordination is ensured by planning, and effective allocation of resources is controlled through bureaucratic systems, with a senior official supervising the efficiency of his subordinates. Normally, the senior tends to be a State official or 
party member (usually the single party in such countries). What risks arise in this environment? In these circumstances businessmen are reduced to mere executives and managers of the plan. They function in a very stable environment and the fact that losses are greater than profits - obtaining additional margins - leads them to have a negative attitude to risk and a great reluctance to accept it. It is said, for example, that there is no unemployment in these countries. There is none outside business because the managers of the plan, due to their fear of not meeting its target, engage more workers than they need, so the unemployment is inside the business. But the most important point is that this aversion to risk results in less initiative, less creativity and, eventually, less progress, especially in technology.

Let us now turn to the decentralised economies having a collective ownership system. Here, an attempt is made to use the market for effective allocation of resources. But once again, despite the fact that they can draw up their own economic plans, the entrepreneurs do not really accept risks since the collective ownership system prevents the risks from reaching the actual individual - the responsibility is accepted at other levels. The usual result is that everything becomes a collective responsibility.

We come now to decentralised economies having private ownership. Here the

market is the co-ordinating factor. Effective allocation of resources is controlled impersonally and democratically by the market. This control may be more or less blind, fair or unfair, but it is done within a free system. Naturally, the question of how risks arise in a market economy also depends on how these markets operate : if the market operates as a real market, and there is true competition, i.e. there are competitive markets, the environment will create risks and uncertainty which the entrepreneur has to accept. In such cases profits - in addition to the controlling function they exercise in the other economic systems - also act as compensation for risk and uncertainty. Hence those who deny the compensatory role of profits vis-à-vis risk and uncertainty are indirectly attacking the market which generates them. Moreover, in these economies, profit also encourages initiative, creativity and economic and social progress. Therefore, collectivist and self-management systems which deny this function of profit (thinking that it is possible for wonderful managers to exist when they are not involved in any risk) are, in the final analysis, advocating a different type of society.

Naturally, there can be a degree of planning in a market economy but it cannot be binding, since it is the entrepreneur who is risking his money, not the State ; thus where private ownership exists, planning cannot be binding. But it must be admitted that better planning reduces the risks and uncertainties of the economic system. The economic programmes of governments should be like navigation charts which show the firms what course to plot, but leave them to run their own risks, without calling constantly on the Coast Guards, as they would do in an interventionist-type economy. When planning goes beyond these limits, risk and uncertainty are gradually eliminated and entrepreneurs develop attitudes leading to co-operation rather than competition. Furthermore, with economic systems having extensive intervention, the entrepreneur spends much more time waiting to see ministers than in his own office concentrating on competition and planning his own business. So, as planning and intervention increase, risk and uncertainty decrease and the entrepreneur becomes more of a co-operator than a competitor. 
Of course, socio-economic systems are mixed, not pure. At the present time, there are two opposing types of system. The one claims to be a model of equality in which State or collective ownership predominates. This is the type in which the individual tends to be at the service of the State rather than the State being at the service of the individual; it places great stress on equality (which is not equality in fact because persons who are not equal are treated equally). This type fails to stimulate saving, hard work or initiative; everything that is creative and original is attacked rather than encouraged, and the system tends to organize daily and professional life collectively rather than individually. This type tends to offer us succour rather than security. I agree that in modern society the individual cannot cope with those needs and risks which exceed his capacity; help from the State is needed. It would be unfair for the State not to provide certain minimum guarantees covering people against events beyond their control in which they cannot intervene. But State aid must cease where the individual and his family are in a position to act on their own responsibility, without needing the community. The present world crisis stems from the tenets held by these types, where more energy is spent on distribution than on production. To sum up, it can be said that it is impossible to raise questions of risk and uncertainty without taking into account the socio-economic environment, at international as well as national level, in which decisions have to be taken.

What bearing has this on insurance? A great deal. Not all risks occurring in economic and social life are insurable immediately. We have already drawn attention to the statistical and actuarial conditions necessary for a risk to be insurable. What happens when competitive types of society predominate over more egalitarian ones ? Well, greater risk and uncertainty produce men with initiative, capable of acting and accepting risks. It is true that society must also remember that these risks (for example, nuclear risks) must be reduced, controlled and anticipated. Then the insurance sector starts dealing with them, assessing them and taking steps to make them insurable - that is, to forestall their economic consequences. This is where insurance is closely linked with economic and social development. It is not just that greater economic and social development is accompanied by greater insurance development, but that insurance has a reciprocal impact on economic and social development. For example, if we take the investment sector, we find that insurance ensures that a number of risks can be taken and this encourages willingness to invest. Many investments are made because many of the risks inherent in the investment process are insurable. Risk and uncertainty have their price, which is reflected in the insurance premium. As regards social progress, insurance enables the individual to draw up his economic plan or family budget under which many of the risks facing him can be transferred to insurance, so that with the rest of his budget he can improve his standard of living. I need hardly mention the export sector, with insurance of export credits and currency exchange risks. In the final analysis, insurance is a source of economic and social development, and progress made in the economic and social field is paralleled by the development of insurance. Proof of this can be seen in the far greater development of insurance in the market or free economies than in the more collectivist economies.

In conclusion, I would say that we are in a very changeable and increasingly uncertain world. All this means that the individual must be well-informed in order to offset this kind of degradation of the outside world, and those risks and uncertainties 
surrounding him. Thus he can compensate for the increased risk and uncertainty from the outside world. In Ciencia de la direccion y formacion del dirigente (Cunef, Serrano Anguita 13, Madrid), I wrote : "I believe that, in the future, the strength of a country. will lie not so much in its natural and human resources as in having men with initiative, the capacity for decision making, a flexible mentality and great powers of adaptation to the constant changes in the world surrounding us". 